\section{Germination of Hormocysts of Scytonema javanicum and the Function of Blue-green Algal Heterocysts}

Heterocysts are the most distinctive cells of the bluegreen algae, Cyanophyta, where they occur in the great majority of the filamentous species. There have been many hypotheses regarding their function, but none of these has been widely accepted and there is fairly general agreement with the conclusion of Fritsch ${ }^{1}$ that heterocysts are still "a botanical enigma". De Pumaly ${ }^{2}$, however, has presented evidence for an essentially mechanical function of the heterocysts and he has compared them with the rhizoids of other algae. The observations reported here are in general agreement with this interpretation of heterocysts as attachment organs, but suggest that their function is distinct from that of ordinary rhizoids.

The observations were made on unialgal cultures of Scytonema javanicum (Kützing) Bornet, originally prepared from culture $B 1473 / 1$ supplied by the Cambridge Culture Collection of Algae and Protozoa. The experimental cultures were grown on a simple basal inorganic medium containing: $\mathrm{K}_{2} \mathrm{HPO}_{4}\left(0.002\right.$ per cent), $\mathrm{MgSO}_{4}$. $7 \mathrm{H}_{2} \mathrm{O}\left(0.002\right.$ per cent), $\mathrm{NaNO}_{3}(0.02$ per cent), agar $(0.8$ per cent $)$. This medium was modified from a Cambridge Culture Collection medium by substitution of the $\mathrm{KNO}_{3}$ by an equivalent amount of $\mathrm{NaNO}_{3}$, on the basis of the known sodium requirement of various blue-green algae. Two separate media were prepared from tho basal medium by addition of either $(a)$ a trace element solution, or (b) 10 per cent by volume of a stock soil extract solution. Parallel cultures, on each medium, were grown both in the north window of the laboratory, with only natural daylight, and under fluorescent lighting, at approximately 200 foot-candles, in a culture room with a temperature regulated at $24^{\circ} \pm 2^{\circ} \mathrm{C}$. The cultures were started on $30 \mathrm{ml}$. of media, in $10 \mathrm{~cm}$ Petri dishes, from small inocula, three evenly spaced inocula per Petri dish.

The cultures grew well under all four treatments forming circular brown colonies on the surface of the agar media. Microscopic examination of the cultures, after 2 months, showed that many hormocysts were present on the surface of the agar, beyond the macroscopically visible margin of the colonies. From the position of the hormocysts it seemed likely that they had been produced by the encystment of motile hormogonia migrating from the colonies.

A considerable proportion of the hormocysts had begun to germinate by protrusion of cell filaments from both

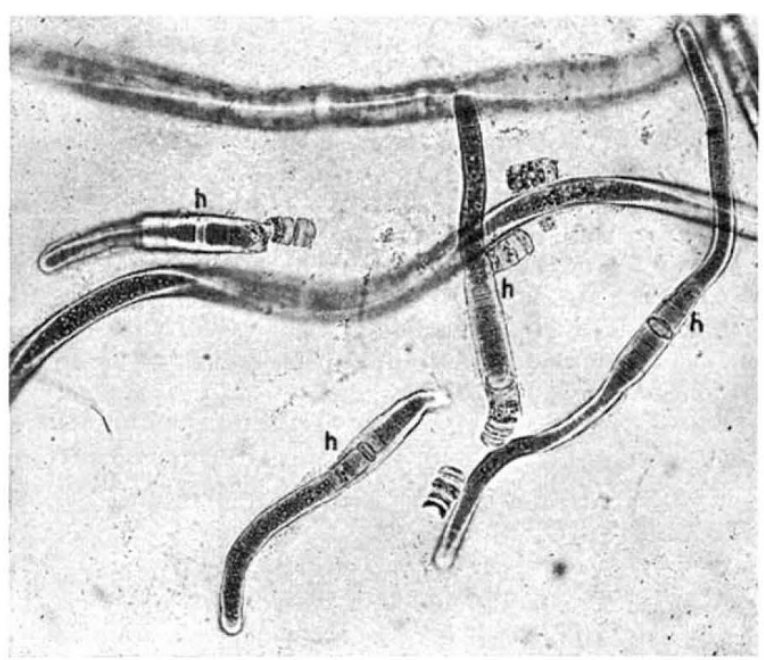

l'ig. 1. Scytonema javanicum. Agar mount of living material showing four germinating hormocysts, each with a median heterocyst $(h)$ ends of the multicellular cysts, each filament growing beyond the fairly thick sheath and pushing aside a cap of dead flattened cells which had previously formed at the end of the cyst (Fig. 1). An interesting feature of these germination stages was that in every one examined a median heterocyst had developed, and as a consequence of its close union with the sheath evidently provided a secure central attachment for the emergent filaments.

In similar cultures of Calothrix anomala Mitra (nomen nudum), Cambridge Collection 1410/4, the formation of one or more basal heterocysts during the germination of few-celled hormogonia was often observed, but is not described in detail here because similar observations have been recorded in the literature for many other species of blue-green algae.

These findings, and many others discussed by de Pumaly $^{2}$, indicate that heterocysts indeed function as attachment organs; but my observations on Scytonema suggest that heterocysts are primarily concerned with the attachment of growing trichomes to the sheath material, rather than in acting as rhizoids as proposed by de Pumaly. In attached species it is the sheath that provides the direct connexion to the substratum.

I thank Mr Geoffrey Grange for the photograph reproduced in Fig. 1 .

Department of Cryptogamic Botany,

A. Allsopp

University of Manchester.

Received September 23, 1968.

${ }^{2}$ Fritsch, F. E., Proc. Linn. Soc. Bot., 162, 194 (1951).

2 de Pumaly, A., Le Botaniste, 41, 209 (1957).

\section{Is the Heterocyst the Site of Nitrogen Fixation in Blue-green Algae?}

MANY blue-green algae produce a characteristic type of cell with rather hyaline contents and a thick, refractive wall (Fig. 1) to which the name heterocyst has been given. Heterocysts are formed from vegetative colls only in filamentous forms. It has been suggested that they are reproductive structures ${ }^{1}$, are involved in spore formation ${ }^{2,3}$ or that they are storage cells ${ }^{4}$, but on the whole the various explanations for their function have been unconvincing, and in reviewing the situation in 1951 Fritsch described them as a "botanical enigma"s.

In a previous communication ${ }^{6}$ two of us reported on a method of "differential cell disruption" for the isolation of heterocysts from the filaments of Anabaena cylindrica. These isolated heterocysts were tested for nitrogen fixation using the nitrogen-15 technique, but no activity was detected. We have now found, however, using the nitrogen-15 method and the more sonsitive acetylene reduction technique ${ }^{7,8}$, that the nitrogenase activity in all of the algal material is lost completely during the initial stages of the isolation procedure, in which heterocysts are separated from adjacent vegetative cells. At present we have no conclusive evidence from work on heterocyst isolates on the location of the nitrogen-fixing system in blue-green algae, but we havo collated the following evidence which strongly suggests that it is sited in the heterocyst.

The main feature which suggests that heterocysts may fix nitrogen is the relationship between the possession of heterocysts by a blue-green alga and its capacity to fix nitrogen. All the strains of blue-green algae (about forty) for which there is unequivocal proof of nitrogen fixation are heterocystous algae and belong to one of the families Nostocaceae, Scytonemataceae, Stigonemataceae or Rivulariaceae $e^{\mathbf{1 0}}$. Until recently the evidence for a direct relationship betwcen the presence of heterocysts and 